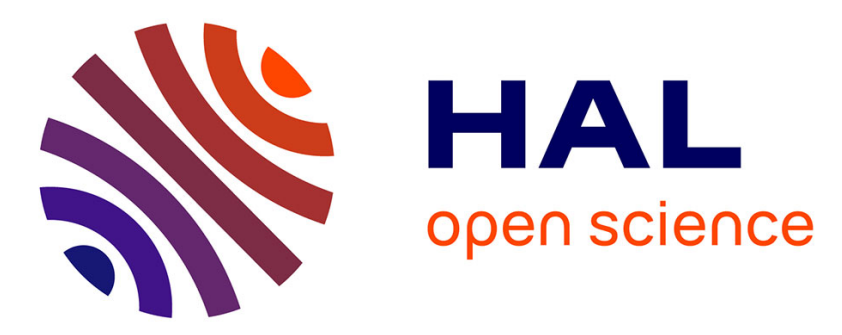

\title{
On the nonlinear dynamics of a bi-stable piezoelectric energy harvesting device
}

\author{
João Peterson, Vinicius Lopes, Americo Cunha Jr
}

\section{To cite this version:}

João Peterson, Vinicius Lopes, Americo Cunha Jr. On the nonlinear dynamics of a bi-stable piezoelectric energy harvesting device. 24th ABCM International Congress of Mechanical Engineering (COBEM 2017), Dec 2017, Curitiba, Brazil. 10.26678/abcm.cobem2017.cob17-1570 . hal-01633207

\section{HAL Id: hal-01633207 https://hal.science/hal-01633207}

Submitted on 11 Nov 2017

HAL is a multi-disciplinary open access archive for the deposit and dissemination of scientific research documents, whether they are published or not. The documents may come from teaching and research institutions in France or abroad, or from public or private research centers.
L'archive ouverte pluridisciplinaire HAL, est destinée au dépôt et à la diffusion de documents scientifiques de niveau recherche, publiés ou non, émanant des établissements d'enseignement et de recherche français ou étrangers, des laboratoires publics ou privés.

$$
\text { Copyright }
$$




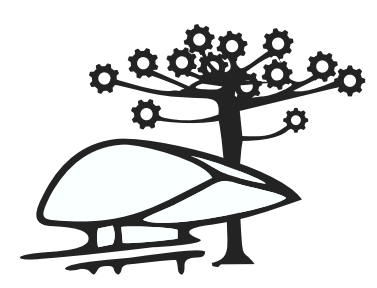

\section{ON THE NONLINEAR DYNAMICS OF A BI-STABLE PIEZOELECTRIC ENERGY HARVESTING DEVICE}

João Victor Ligier Lopes Peterson

Vinicius Gonçalves Lopes

Americo Cunha Jr

NUMERICO - Núcleo de Modelagem e Experimentação Computacional

Universidade do Estado do Rio de Janeiro (UERJ)

joao.peterson@uerj.br

vinicius.lopes@uerj.br

americo@ime.uerj.br

Abstract. This work deals with the dynamics of a nonlinear piezoelectric energy harvesting device, intending to map configuration of parameters able to provide chaotic and non-chaotic response behavior. The dynamics in explored changing forcing amplitude and excitation frequency. Bifurcation diagrams and basins of attraction are computed, and their analysis allow to identify regions of chaotic and regular dynamics.

Keywords: non-linear dynamics, energy harvesting, bi-stable system, piezo-magneto-elastic beam, chaos

\section{INTRODUCTION}

Energy harvesting is a process in which a small amount of energy from an abundant source is collected via a device called harvester, stored into a battery or capacitor, and then used by another device with low power demands (Priya and Inman, 2009; Caliò et al., 2014). Although conceptually simple, this technology is capable of providing energetic solutions to several interesting applications that goes from nanosystems (Koka et al., 2014; Seol et al., 2013; Wang and Song, 2006) to wireless networks (Kausar et al., 2014).

Among all the energy harvesting devices that exist today, those based on bi-stable configurations (Cottone et al., 2009; Erturk et al., 2009) are among the most promising from the efficiency point of view, being widely studied in the literature (Leite et al., 2016; Peterson et al., 2016; Lopes et al., 2017).

This work intend to study in deep the nonlinear dynamics of the piezo-magneto-elastic energy harvesting device proposed by Erturk et al. (2009). For this purpose, the dynamical system is investigated by means of bifurcation diagrams and basins of attraction, seeking to analyze the qualitative nature of the system response, to identify configurations associated to chaotic behavior and sensibility to the initial conditions.

Next section is devoted to physical and mathematical modelling; third one brings numerical experiments and results discussions. Finally, last section presents work main conclusions and future perspectives.

\section{NONLINEAR DYNAMICAL SYSTEM}

\subsection{Physical model}

The physical system of interest in this work is depicted in Figure 1. It consists of a rigid base, where it is fixed a ferromagnetic beam undergoing lateral vibrations, driven by an external periodic force. A pair of magnets, placed in lower part of the rigid base, induces large amplitude movements. At the top of structure, next to beam fixed edge, a pair of piezoelectric material plates is responsible for conversion of mechanical energy into electrical potential.

\subsection{Mathematical model}

The dynamic of the system of interest is described by the following system of ordinary differential equations

$$
\begin{aligned}
& \ddot{x}+2 \xi \dot{x}-\frac{1}{2} x\left(1-x^{2}\right)-\chi v=f \cos \Omega t, \\
& \dot{v}+\lambda v+\kappa \dot{x}=0,
\end{aligned}
$$

where $x$ represents beam's extreme displacement, $\xi$, the mechanical damping ratio, $\chi$, a piezoelectric coupling term in mechanical equation, $f$, the amplitude of excitation, $\Omega$, the forced excitation frequency, and $v$, the output voltage; 


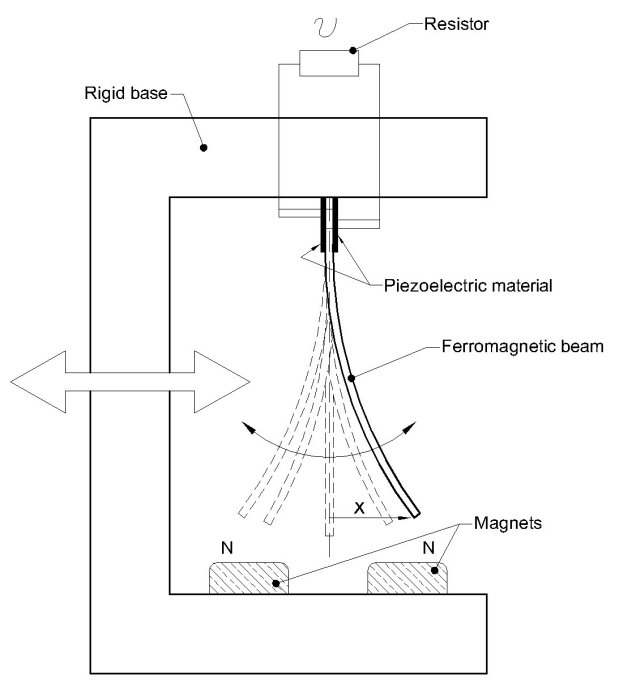

Figure 1. Schematic representation of the piezo-magneto-elastic energy harvesting device (Erturk et al., 2009).

in electrical circuit equation, $\kappa$ means a piezoelectric coupling term and, finally, $\lambda$ is a reciprocal time constant. All parameters are dimensionless, assumed initially as $\Omega=0.8, \xi=0.01, \chi=0.05, \kappa=0.5$ and $\lambda=0.05$.

The forcing amplitude interval and initial conditions for displacement, velocity and voltage, respectively denoted by $x_{0}, \dot{x}_{0}$ and $v_{0}$, are specified in next section.

\section{RESULTS AND DISCUSSION}

\subsection{Bifurcation diagrams}

In this section the dynamics of the system of interest is explored through bifurcation diagrams. Two different methodologies, here referred as forward and backward, are employed to compute these diagrams. Forward ones considers an increasing sequence a control parameter (excitation frequency), while backward a decreasing one. Is assumed a set of 1200 different values uniformly distributed from a minimum frequency of $\Omega=0.3$ until a limit value of $\Omega=1.4$. In all the cases initial conditions are $x_{0}=1, \dot{x_{0}}=0$ and $v_{0}=0$, and the first ninety percent of the time-series is neglected (to avoid the transient).

In the Figure 2 the reader can see bifurcations diagrams which shows the beam displacement as function of the excitation frequency, for a fixed excitation amplitude of $f=0.05$. Computing sequence clearly interferes in results obtained: an bifurcation can be observed only in backward case, between $\Omega=0.72$ and $\Omega=0.76$. Despite of this, the system response remains regular, in both situations, for entire interval.

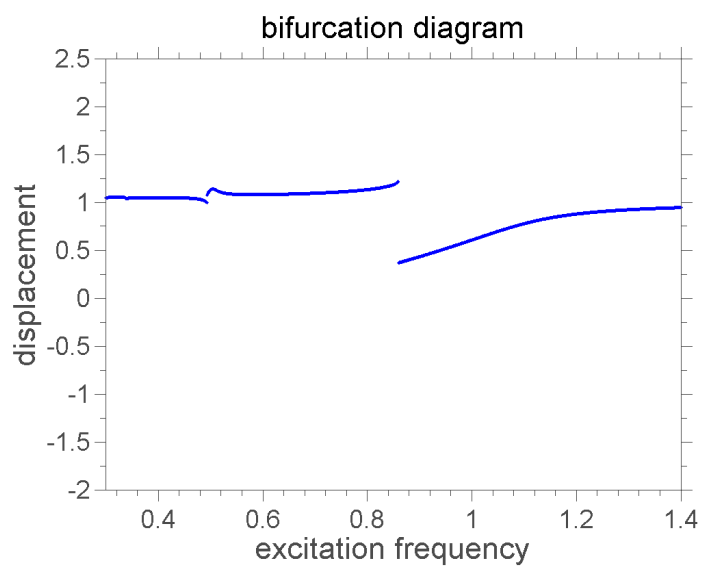

(a) Forward case

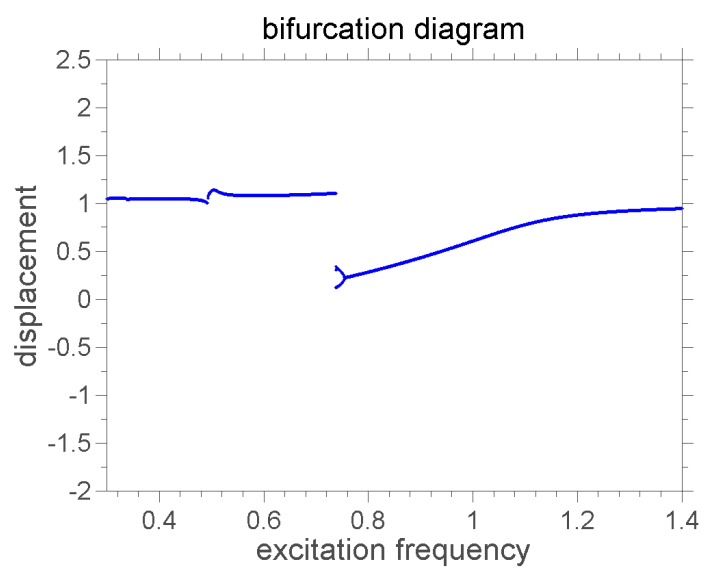

(b) Backward case

Figure 2. Bifurcation diagrams for displacement as function of excitation frequency with $f=0.050$. 
In the Figure 3 are presented other two bifurcation diagrams, now, for $f=0.083$. A chaotic dynamic, represented by a blurred region, can be observed both forward and backward cases nearby $\Omega=0.8$. Although, regular pattern between 0.36 and 0.78 presents an opposite behavior in forward case in comparison with backward one; last methodology also allows to detect an small set of regular solutions around $\Omega=0.4$.

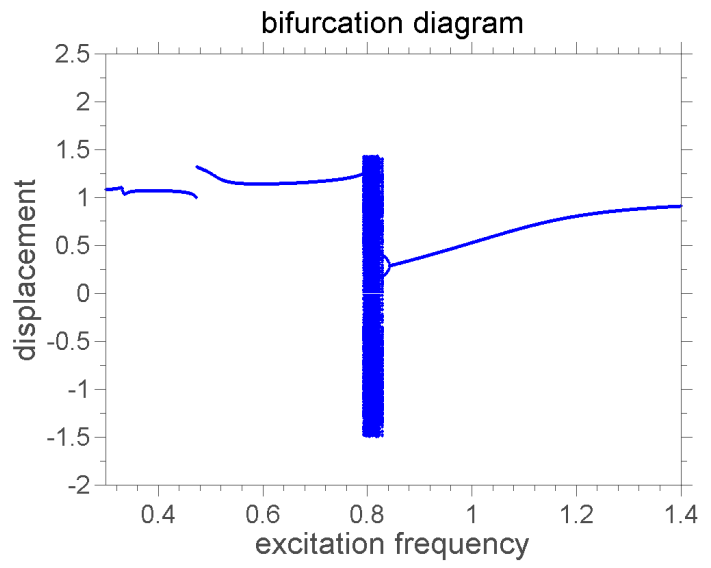

(a) Forward case

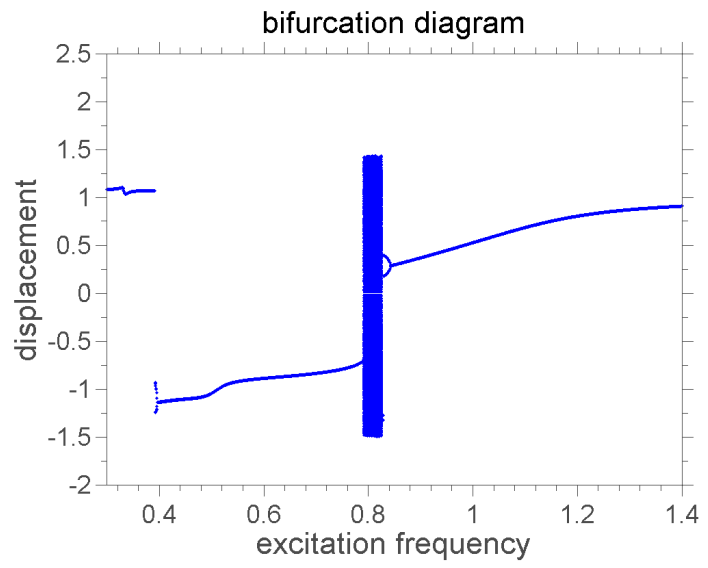

(b) Backward case

Figure 3. Bifurcation diagrams for displacement as function of excitation frequency with $f=0.083$.

Figure 4 brings results for $f=0.1$. Here obtained diagrams change completely from a methodology to another. For entire analyzed interval, forward solution provides an regular dynamics for system response. Discontinuities are observed around $\Omega=0.44$ and $\Omega=0.78$. Backward case allows to identify an chaotic region for excitation frequencies from approximately 0.78 to 0.88 , while a single discontinuity can be observed around $\Omega=0.36$.

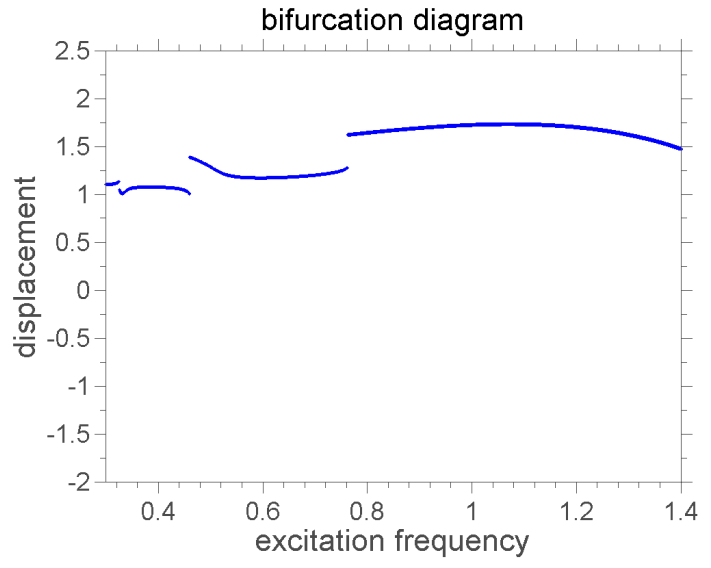

(a) Forward case

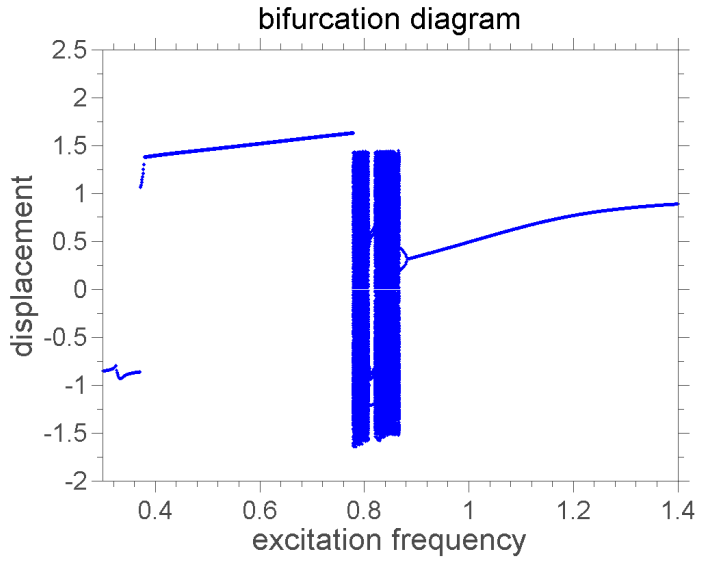

(b) Backward case

Figure 4. Bifurcation diagrams for displacement as function of excitation frequency with $f=0.100$.

Finally, the Figure 5 presents diagrams for $f=0.115$. As in last case, backward methodology presents a richer dynamics regards to chaotic response for same region. A set of points appears nearby $\Omega=0.36$, representing multiples solutions for this excitation amplitude values region. Forward case diagram shape does not presents significant changes beyond discontinuities position in comparison with that obtained for $f=0.100$.

Results present in Figures 4 and 5 reinforce system dynamics complexity: for the same excitation frequency and forcing amplitudes values, in each case, obtained diagrams change significantly depending on the way analysis interval is evaluated. Even in the earlier cases, presented by Figures 2 and 3, small dynamics phenomena are captured, in general, for backward analysis while forward suppresses them.

\subsection{Basins of attraction}

This section presents results of the analysis of basins of attraction in displacement versus velocity plane using an uniform 1400 x 1400 grid of points. 


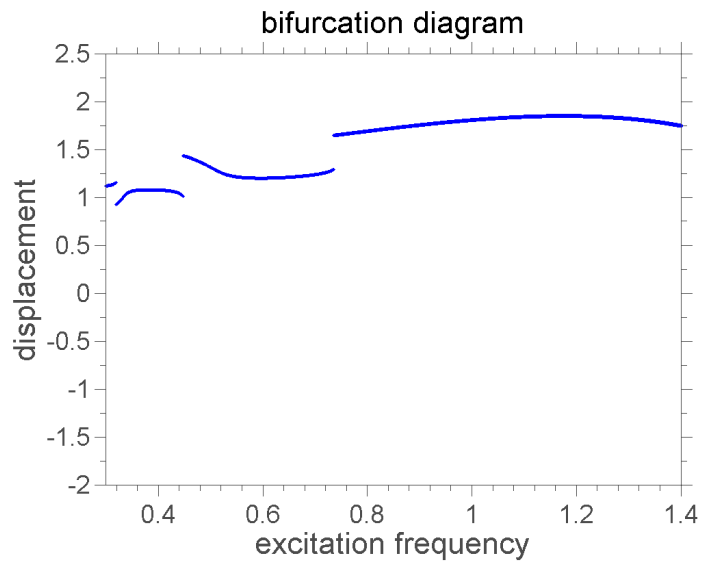

(a) Forward case

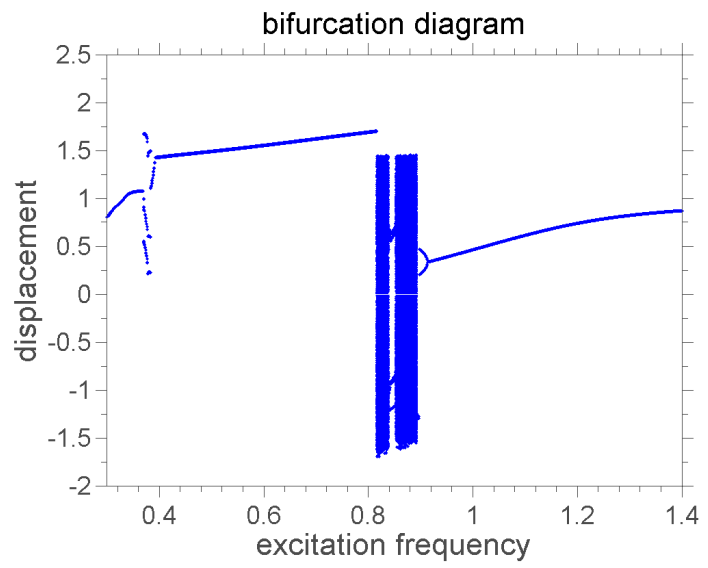

(b) Backward case

Figure 5. Bifurcation diagrams for displacement as function of excitation frequency with $f=0.115$.

In Figure 6 the reader can observe the basins of attraction for $f=0.05$ and the corresponding attractors, which corresponds to regular behavior. It is important to notice that a minimum change in the set of initial conditions can lead to a completely different attractor, characterizing deep sensitivity to these parameters.
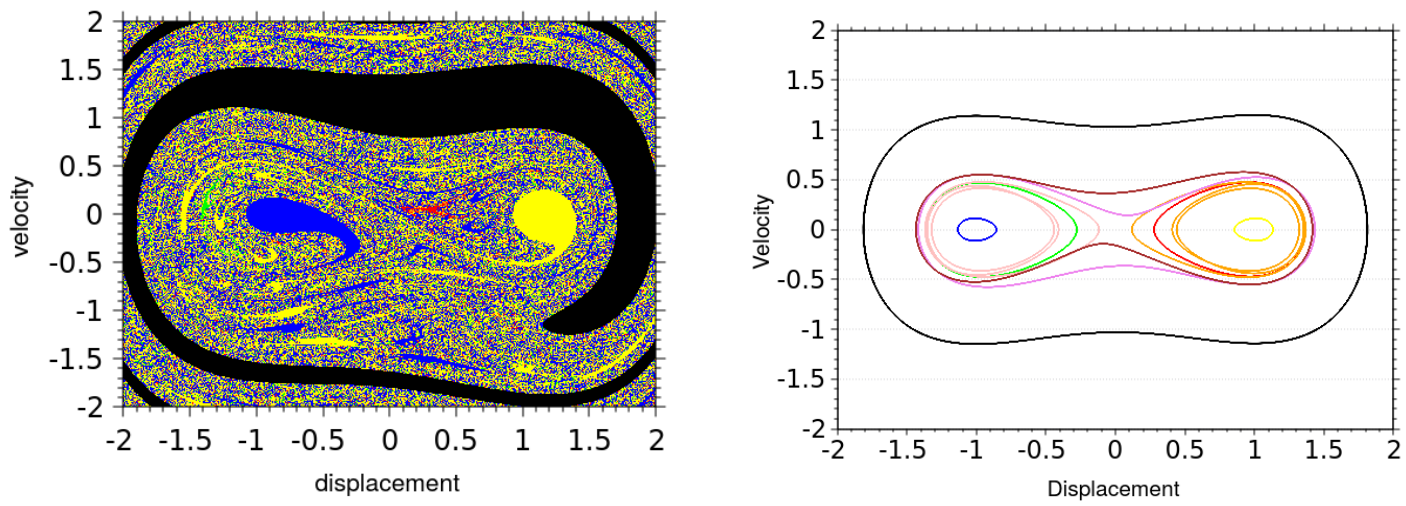

Figure 6. Basins of attraction in displacement versus velocity plane for $f=0.05$ and the corresponding attractors.

The pictures in Figure 7 are clippings from the basins presented in Figure 6, trying to characterize the red structure seen below. It is easy to see that the aforementioned structure is very well delimited.

On the other hand, Figure 8 shows basins of attraction for different excitation amplitudes $(f=0.083, f=0.1$ and $f=0.115$ ). In this case, the initial conditions painted white lead to chaotic attractors, whereas the ones painted black to a regular attractor.

\section{FINAL REMARKS}

This work have analyzed the nonlinear dynamics of an bi-stable energy harvesting device by means of bifurcation diagrams and basins of attraction. The dynamics behavior was addressed in a way to characterize the sensibility of the system response to the initial conditions and the influence of excitation parameters over chaos incidence. Bifurcation diagrams were built under two distinct methodologies for a set of four different forcing amplitude values, demonstrating dynamics complexity and results sensibility. Basins of attraction were computed for the same forcing amplitude values, allowing to identify initial conditions sets of values which provides chaotic responses. In the future work, the authors intend to investigate in deep the nonlinear structure of the dynamical system and implement power electronics technics to improve delivered energy quality and output power. 

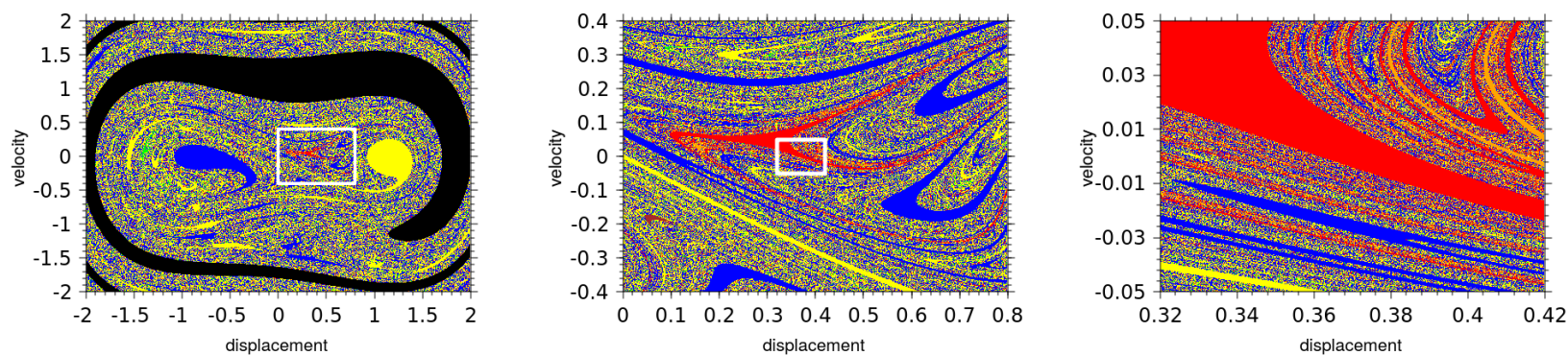

Figure 7. Clippings of the basins of attraction in displacement versus velocity plane for $f=0.05$.
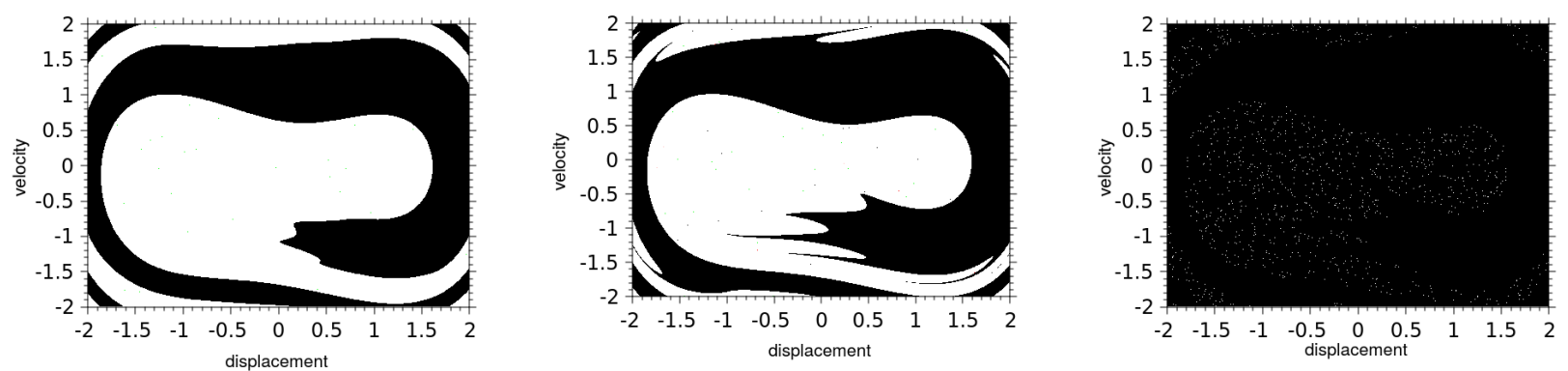

Figure 8. Basins of attraction in displacement versus velocity plane for different excitation amplitudes: $f=0.083$ (left), $f=0.1$ (right) and $f=0.115$ (bottom).

\section{ACKNOWLEDGEMENTS}

The authors are indebted to the Brazilian agencies CNPq, CAPES and FAPERJ for financial support given to this research. They also thank Mr. Thiago Leite, Prof. Aline Souza and Prof. Adriano Fabro, from University of Brasília (UnB), for the enlightening comments about the problem addressed in this work.

\section{REFERENCES}

Caliò, R., Rongala, U.B., Camboni, D., Milazzo, M., Stefanini, C., de Petris, G. and Oddo, C.M., 2014. "Piezoelectric energy harvesting solutions". Sensors, Vol. 14, No. 3, pp. 4755-4790. ISSN 1424-8220. doi:10.3390/s140304755. URL http://www.mdpi.com/1424-8220/14/3/4755.

Cottone, F., Vocca, H. and Gammaitoni, L., 2009. "Nonlinear energy harvesting". Phys. Rev. Lett., Vol. 102, p. 080601. doi:10.1103/PhysRevLett.102.080601. URL https://link.aps.org/doi/10.1103/PhysRevLett.102.080601.

Erturk, A., Hoffmann, J. and Inman, D.J., 2009. "A piezomagnetoelastic structure for broadband vibration energy harvesting". Applied Physics Letters, Vol. 94, No. 25, p. 254102. doi:10.1063/1.3159815. URL http://dx.doi.org/10.1063/1.3159815.

Kausar, A.Z., Reza, A.W., Saleh, M.U. and Ramiah, H., 2014. "Energizing wireless sensor networks by energy harvesting systems: Scopes, challenges and approaches". Renewable and Sustainable Energy Reviews, Vol. 38, No. Supplement C, pp. 973 - 989. ISSN 1364-0321. doi:https://doi.org/10.1016/j.rser.2014.07.035. URL http://www.sciencedirect.com/science/article/pii/S1364032114004870.

Koka, A., Zhou, Z., Tang, H. and Sodano, H.A., 2014. "Controlled synthesis of ultra-long vertically aligned batio 3 nanowire arrays for sensing and energy harvesting applications". Nanotechnology, Vol. 25, No. 37, p. 375603. URL http://stacks . iop. org/0957-4484/25/i=37/a=375603.

Leite, T., de Paula, A.S., Fabro, A.T. and Savi, M., 2016. "A numerical analysis of the electrical output response of a nonlinear piezoelectric oscillator subjected to a harmonic and random excitation". In XXXVII Iberian Latin American Congress on Computational Methods in Engineering (CILANCE 2016).

Lopes, V.G., Peterson, J.V.L.L. and Cunha Jr, A., 2017. "Numerical study of parameters influence over the dynamics of a piezo-magneto-elastic energy harvesting device". In XXXVII Congresso Nacional de Matemtica Aplicada e Computacional (CNMAC-2017).

Peterson, J.V.L.L., Lopes, V.G. and Cunha Jr, A., 2016. "Maximization of the electrical power generated by a piezomagneto-elastic energy harvesting device". In XXXVI Congresso Nacional de Matemtica Aplicada e Computacional (CNMAC-2016). URL http://dx.doi.org/10.5540/03.2017.005.01.0200. 
Priya, S. and Inman, D.J., 2009. Energy Harvesting Technologies. Springer.

Seol, M.L., Choi, J.M., Kim, J.Y., Ahn, J.H., Moon, D.I. and Choi, Y.K., 2013. electric nanogenerator with a nanoforest structure". Nano Energy, Vol. 2, No. 6, pp. 1142 - 1148. ISSN 2211-2855. doi:https://doi.org/10.1016/j.nanoen.2013.04.006. URL http://www.sciencedirect.com/science/article/pii/S2211285513000773.

Wang, Z.L. and Song, J., 2006. "Piezoelectric nanogenerators based on zinc oxide nanowire arrays". Science, Vol. 312, No. 5771, pp. 242-246. ISSN 0036-8075. doi:10.1126/science.1124005. URL http://science.sciencemag.org/content/312/5771/242.

\section{RESPONSIBILITY NOTICE}

The authors are the only responsible for the printed material included in this paper. 